\title{
ROMA HUKUKUNDA USUCAPIO PRO DONATO VE PRO DOTE.
}

\author{
Asis. Dr. Pertev SUBASI
}

Medenî Kanunumuzun 701 inci maddesine göre: başkasının menkul bir malını nizasız ve fasılasız mülkümdür diye ve hüsnüniyetle beş sene yedinde bulunduran kimse o mala müruruzaman sebebiyle malik olur. Bu maddenin muhtevasından sarih surette anlaşıldığı veçhile, iktisabi müruruzamanın şartları şunlardır: 1 - Kendisini hüsnüniyetle malik sanmak 2 - Malı nizasız ve fasılasız yedinde bulundurmak $3-\mathrm{Bu}$ zilyetliğin muayyen bir müddet devam etmesi. Orta Çă̆ hukukçulari bu şartlara : fides, possessio, tempus, derler. Fakat iki şart daha ilâve ederler: res habilis, titulus. Zira tefsir ettikleri Roma hukukunda, bu gïnkü iktisabi müruruzamana tekabül eden usucapio, bu son iki şartı da ihtiva eder.

Roma hukukunda, herhangi bir menkul, müruruzaman ile iktisap olunamaz. Usucapio edilecek mal habilis olmalıdır, yani çalınmış, veya cebir ile elde edilmiş olmamalıdır [ $\left.{ }^{1}\right]$. Diğer taraftan, hür insanlar, diṇ̂̂ ve mukaddes eşyalar, provinste bulunan arazi kabili iktisap değildirler [²]. Çalınmış veya cebir ile elde edilmiş malı yalnız fail değil, hüsnüniyet sahibi zilyet dahi usucapio yoliyle iktisap edemez [ $\left.{ }^{3}\right]$.

Diğer bir şart ta titulustur. Usucapio'nun meşru bir sebebi, bir illeti olmalrdir (justa causa usucapionis). Iktisabi müruruzaman bir híbeye (pro donato), bir tediyeye (pro soluto), bir iştiraya (pro emptore).. vs, müstenit olmalıdrr.

Biz bu yazımizda bu sebeplerin biribirine bazi noktalardan benziyen iki tanesini, bağışlama ve cihazı (pro donato, pro dote) tetkik edeceğiz.

Bağışlama ile bir kimse bir malını muayyen bir şahıs lehine ve jvazsız olatak terk eder. Roma hukukunda, bağışlama ya teslim suretiyle,

[1] Gaius, inst, I1, 45.

[2] Gaius, inst, II, 46-18.

$\left[{ }^{2}\right]$ Gains, inst, L], 49. 
veya taahhïdi şekilde olabilir. Biz burada yalnız teslim suretiyle yapilan bağışlamayı nazara alacağız. Zira mevcut metinler usucapio bahsinde yalnız bağışlamanın bu şeklinden bahis ediyorlar. Taahhüdi hibeden bahsetmemelerinin sebebi kolayca izah edilebilir. Çünkü taahhüi (stipulatio) bir bağlam vücude getirir ve bu bağlam ancak taahhüt edilen şeyin aynen yerine getirilmesiyle çözülebilir (Solutio). Roma hukukçuları ise solutio'yu usucapio'nun ayri bir sebebi olarak ele aliyotlar $\left[{ }^{4}\right]$.

Bağışlamaya ait metinleri gözden geçirelim. Hukukçu Paulus'a göre, kendisine bağışlama olarak bir şey teslim edilen kimse o şeyi hibeye muistenit usucapio ile iktisap eder. (Dig. 41, 6, 1. - Pro donato is usucapio qui donationis causa res tradita est). Hibe olduğunu zan ve farz etmek kâfi değildir. Hakikatte bir bağışlama yapılmış olması lâzımdı: (nec sufficit opinari, sed et donatum esse oportet). Paulus, şu misali aliyor:

Eğer baba, velâyeti altında bulunan oğluna bir hibe yapar ve sonra vefat ederse, oğlu bağışlananı hibeye müstenit bir usucapio ile iktisap edemez, çünkü hakikatte hiçbir bağışlama olmamıştır. (Si pater filio quem in potestate habet donet, deinde decedat, filius pro donato non capiet usu, quoniam nulla donatio fuit). Bağışlama olmayışının sebebi ise âşikârdır: Malûm olduğu veçhile, Roma hukukunda, velâyet altında bulunan oğullar, kaideten, kendi hesaplanına değil, ancak paterfamilias'in hesabına mal iktisap edebilirler. Şu halde velâyeti altında bulunan oğluna bağışlama yapan baba, kendi kendine bir hibe yapmı̧ olur ki, böyle bir hukuki muamele tasavvur edilemez. Gerçi vefatında, oğlu sui juris olacak, ve o sıfatla, kendi hesabına iktisap etmeğe muktedir olacaktır. Fakat, bu metinden anlaşıldığı veçile, hibenin olup olmadığına hükmetmek için onun yapıldığx zamandaki durum göz önünde tutulmalıdır.

Bu dediğimizi başka bir metin ilk bakışta tekzip ediyorsa da, asItnda Paulus'un misaline zit addedilemez. Pomponius'a ait bu metinde deniliyor ki: Eğer bir baba, velâyeti alunda bulınan krzına bir bağıșlama yapar ve sonra onu mirastan mahrum ederse, diğer mirasçı o hibeyi tasdik ettiği takdirde, bağışlamaya müstenit usucapio tasdik günüinden itibaren mümkün olur (Dig. 41, 6, 4. - Si pater filiae donaverit quae in potestate eius erit, et eam exheredaverit; si id heres eius ratum habeat, exinde ea usucapiet donationem, qua ex die ratam heres habuerit).

Bu metni şöyle izah edebiliriz: Baba tarafından velâyeci altındaki kızına yapılan bağışlama, paterfamilias tarafından kendi şahsına yaprl-

[‘] Dig., Pro Soluto, 41, 3, 46. 
mış addolunur. Dolayısiyle, muteber bir hukuki muamele değildir. Kızın mırasçılıktan mahrum edilmesi bu bağışlamayı muteber kılamaz. (Halbuki aksi tasavvur edebilirdi. Çünkü mirasçı sıfatiyle babasıñn şahsiyẹtini devam ettiren kTz, mirastan iskat ile onunla ilg!sini kesmiş addolunabilirdi.) Fakat bilâhare paterfamilias'ın mirasçısı o bağış̧anan malı geri istemezse, o vakit, kız hibeye müstenit usucapio ile onu iktisap edebilecektir. Ama hangi hibeye istinat ederek? Babasının hibesine değil, çünkü-o hibe aslında muteber değildir. $O$ halde usucapio'nun sebebi mirasçının bağışlamasıdır. Mirasçı malı geti istememekle kendisi bir hibe yảpmış addolunur, ve zaten onun için iktisabî müruruzaman ancak o andan itibaren başlar. Görülüyor ki Pomponius ile Paulus'un dedikleri arasında hiçbir tezat yoktur.

Paulus'un metnine dönelim. Bu hukukçu misaline devam ederek diyor ki: Kari ve koca arasında bir bağışlama [ [ $\left.{ }^{5}\right]$ olursa, usucapio münkatidir ( $\mathrm{Si}$ inter virum et uxorem donatio sit, cessat usucapio).

Bunun sebebi karı koca arașındaki bağışlamaların klâsik devirde men edilmiş olmasıdir.

Bağışlamadan sonra karı ve koca boşanırlarsa, usucapio kabil olacak mıdır? Yine Paulus'a göre, Cassius menfi cevap vermiştir, çünkü boşanmakla zilyedliğin sebebi değişmiş olmaz, binaenaleyh usucapio yine meşru olmiyan bị sebebe müstenittir; fakat boşanmadan sonra, koca karısının o malı yedinde bulundurmasına müsaade ederse, o adnan itibaren usucapio mümkün olacaktır, çünkü o zaman koca bir bağışlama yapmış addolur. Görülüyor ki bu misal Pomponius'un verdiği misali teyit etmektedir.

Fakat daima hakkaniyeti göz önünde tutan Roma hukukçuları, kanunların lâfzına değil, ruhuna ehemmiyet verdiklerinden dolayı, karı koca arasındaki hibelerin memnuniyetinin sebebini araştırmışlar ve o memnuiyetin şümulünü daraltmışlardır. Karı koca arasında bağışlamaların yasak "olmasının sebebi hukukģu Ulpianus'un fikrince aralarındaki karşılıklı muhabbeti mütekabilen bozması kaygısıdır (ne mutuo amore invicem spoliarentur) $\left.{ }^{6}\right]$. Imparator Caracalla daha makul bir sebep veriyor: karı koca dan iyi kalplisinin fakirleşmesine, açıkgözlüsünün

[5]. Tahî̉ bütïn bu misallexde bağışlıyan tasarruf etmeğe hakkı olmaxtığı bir seyi bağsşliyor, veya onu temlik ederken kanuni sekillere riayet etmyor (meselâ, bir tes mancipi akilsiz bir devrü temlik ile bağışlannyor.) Aksi taktinde, usucapio'dan bahsetmeğe mahal olmaxd.

[6] Dig., de dom. int. vir. et ux., 24, 1, 1. 
zenginleşmesine mâni olmak (ne melior in paupertatem incideret, deterior ditior fieret) $[\tau]$.

Bu son mülâhazadan Roma hukukçuları şu neticeyi çıkarmışlardır: Hibe, bağışlayan karı veya kocayı fakirleştiremezse, muteber adolunacaktır. Şu halde, o hibeye müstenit usucapio'nun da mümkün olacağını Pomponius'a ait metinden anliyoruz: «Koca karisına veya katı kocasina bir bağışlama yaptığı ve bağıșlanan mal aharın olduğu takdirde, Tre batius'un haklı olarak hükmettiği veçhile bağışlayan fakirleşmezse; malı yedinde bulunduran onu usucapio yoliyle iktisap eders (Dig. 41, 6 .3. - Si vir uxori vel uxor viro donaverit, si aliena res donata fuerit, verum est, quod Trebatius putabat, si pauperio is qui donasset non fierit, usucapionem possidenti procedere). Fakat, başka bir hukukçu (Neratius) bazı hallerde, koca fakirleşse dahi, usucapiu'yu meşru addediyor: bir üçüncü şahıs, kocaya ait bir malr, bu keyfiyetten haberdar olmıyarak, karrya bağıslarsa, ve ne koca ne de karı malın kocanın mülkü.olduğunu bilmezlerse, karı tarafindan o malın usucapio'su caizdir (Dig. 24, 1, 44. - Si extraneus rem viri, ignorans eius esse, ignoranti uxori, ac ne viro quidem sciente eam rem sum esse, donaveric, mulier recte eam usucapit). Neratius'un bu hükmü evvelce gördüğümüz metinlere zıt değildir, çünkü burada koca tarafından bir bağıșlama olmamıştır; hibeyi hününiyetle yapan iiçüncii şahtstır, ve usucapio o hibeye, yani memnu olmayan bir sebebe istinaden yapılmıştr. Fakat Neratius daha ileri giderek diyor ki: «keza velâyet altında bulunan kimse, kendini paterfamilias zannederek, kartya bir bağışlama yaparsa, usucapio caizdir»». Bu misal pek de yerinde olmasa gerek. Zira velâyet altından bulunanların bağışlama yapmağa ehliyetleri yoktur. Şu halde usucapio meşru bir sebebe istinat ediyor mu? Neratius menfi cevap veriyor; herhalde şu mantığt yürütüyor: bağışıyan ve bağışlanan hüsnüniyetle bir bağışlama muamelesine girişiyorlar. Bağışlamanın en ehemmiyetli unsuru animus donandi, yani bir malı Ivazsız ve teberru kasdiyle basskasi lehine terk etmek iradesidir. Bu irade misalde mevcuttur. Şu halde, bağışlanan, velâyet altındaki şahsın o iradesine istinaden, mali usucapio suretiyle iktisap edecektir. Fakat ne olursa olsun, meşru sebep mefhumu herhalde Neratius tarafından çok genişletilmiștir. Bir filiusfamiliasın tasarrufi muámeleler yapmağa ehliyeti ofmadığından, onun, hüsnïniyetle de olsa, yaptı̆̆ı bă̆ışlamanın usucapio ya sahih bir sebep teşkil edeceğini kabul etmek biraz güçtür.

Şayet koca veya karr hakiki duruma ittıla ederlerse, daha doğrusu koca malın kendi mülkü olduğunu bilir, ve kadın da bunu bilâhare ve

[?] Dig., de don. int. vir, et ux., 24, 1, 3 pr. 
usucapio tamamlanmadan öğrenirse, vaziyet ne olacaktır? Neratius bu takdirde bir tefrik yapıyor: Eğer koca malın kendi mülkü olduğuna ittıla eder ve ona istihkak dâvasında bulunabilirken ihtiyariyle sarfınazar ederse, ve karısı da bunu bilirse, o vakit usucapio mümkün olmryacaktır, çünkü bu takdirde illet değişmiş ve gayri meşru bir sebep olmuştur. Fakat yalnız kocanın yahutta yalnız kadının bilâhare ıttıla etmeleri usucapio'yu münkati kılmaz. Çünkü kocanın mülk sahibi olduğunu öğrenmesi ne vahibin ne de karının hüsnüniyetini ihlâl etmez, ve karının zilyedliğinin sebebini değiştirmez. Karımn tttrla etmesi ise, ancak onun hüsnüniyetini ortadan kaldırır; fakat bağışlamayı yapan üçüncü şahıstır, ve onun bağışlaması muteber kalır, zira memnu olan, karının kocaya ait herhangi bir malı iktisap etmesi değil, karı koca arasındaki ihtiyari bağışlamalardır. Misâlde ise bağışlama üçüncü şahıs tarafından yaptłmıştır

Bu misal de göstériyorki, Roma hukukçuları birtakım mütalâalarła, usucapio pro donato'nun tatbik sahasında şümulünü genişletmeğe çalışmışlardır.

Usucapio sebepleri arasında bağıșiama ile bazı benzer noktalari olan diğer bir muamele de cihaz dir (usucapio pro dote.)

Bağışlama gibí, cihaz da ya taahhütle, veya doğrudan doğruya teslim ilé resıs edilir. Bizi alâkadar eden teslim suretiyle yapılan cihaz. drr. Çünkü, yalnız bir cihaz taahhüdü mevcut ise-ki buna Romanın klâsik devrinde promissio veya dictio dotis, Justinianus zamaninda ise pactum dotale denirdi-, o vakit usucapio'nun sebebi taahhütten doğan bağın çözülmesi, yani solutio olacaktır. Aynt mütalâayı bağış̧ama için de yürütmüştük.

Fakat cihaz ilè bağışlama arasında ehemmiyetli bir fark vardır ki o da cihazın ivazsız olmatmasıdır. Cihazı, karı veya üçüncü bir şahıs tarafından aile masrafına medar olmak üzere kocaya verilen mallardır diye tarif edebiliriz. Şu halde, cihazdaki ivaz aile masraflarının koca tarafından kendi üzerine alınmasıdır. Gerçi bu adetâ manevî bir ivazdır, fakat usucapio hususunda ehemmiyeti vardur. Zira, usucapio pro dote ancak evliler arasında mümkündür (Dig, 1, 9, 1, 3-4.. inter eos locum habet inter quos est matrimonium).

Fğer evlenme feshedilirse, cihaza müstenit usucapio mümkün olmıacaktır, çünkü cihaz verilmemiş addolunur (quiia et dos nulla sic.) Ulpianus'un Cassius'tan naklettiği bu son cümle, cihaz mefhumunun 
evlenme ile sıkı bir rabıtası olduğunu teyit ediyor. Şu halde eğer bir şahıs kendinin evli olduğunu zanneder, fakat hakikatte ortada bir evlenme bulunmaz ise, usucapio yine mümkün olamıyacaktır.

Fakat aynı metinde, UIpianus, Julianus'tan naklen, usucapio'nun bazı hallerde evlenmeden önce mümkün olabileceğini iddia ediyor $\left[{ }^{8}\right]$ : «Nişanl, yani henüz koca olmıyan kişi, malı cihaza müstenit usucapio ile iktisap edebilir mi diye sual edilmiştir. Ve Julianus demistir ki: eğer nişanlı kız, ancak evlendikleri takdirde malın iktisap edileceği şartiyle onu nişanlısına teslim etmişse, usucapio mümkün değildir. Fakat eğer bu şart sarahaten if ade edilmemişse, o zaman, zannedildiğine göre Julianus malın nişanlı tarafında hemen iktisap edilmesini, ve eğet mal aharın ise, ona usucapio yoliyle malik olmasını caiz kılmıştırs. Ulpianus ilâve ediyor: evlenmeden önce, nişanlı cihaza müstenit bir usucapio ile değil, daha umumi ve mücerret bir sebebe istinaden malt iktisap eder. Bu sebebe Roma hukukçuları «pro suo» diyorlar.

Şu halde, evlenmeden önce derhal iktisap edilmesi iradesiyle nişanlıya bir mal teslim edilmişse, bir cihaz tesis edilmiş addolunmaz. Müstakbel bir hâdisenin (yani evlenmenin) vuku bulacağı ümidiyle alelâde bir devir ve temlik muamelesi önünde bulunuruz. Onun için Ulpianus böyle bir muameleye müstenit usucapio'ya ayrı bir isim veriyori onu "pro suo» terimiyle isimlendiriyor.

Cihazın kıymeti takdir ve tahmin edilitse, ve koca cihazı teşkil eden mallardan değil, onların değerinden mesul tutulursa, vaziyet ne olacaktır? Bilindiği üzere, Roma hukukunda bir malı takdir ve tahmin ettirmek, onu satmaya tekabül eder. Şu halde mallar satılmıs, ve tutarı cihaz olarak verilmis addolunacaktur; fakat bu vaziyet ancak evlenme aktedildikten sonra tahakkuk edecek, ve o vakite kadar satış taliki bir şarta bağlı bulunacaktır. Dolayısiyle şart (yani evlenme) tahakkuk edinceye kadar usucapio mümkün olmiyacaktur. Bunu Paulus'a ait bir metinden anlıyoruz: Eğer takdir ve tahmin edilen mal evlenmeden önce teslim edilmişse, usucapio ne satışa ne de umumi bir sebebe istinaden evlenmeden önce mümküin olmtyacaktır (Dig. 41, 9, 2.-Si aestimata res ante nuptias tradita sit, nec pro emptore, nec pro suo ance nuptias usucapietur).

[8\} Dig. 41,91 1\$2-Est questio volgata an sponsus possit (hoc est qui oondum maritus est) rem pro dote usucapere. Et lulianus inquit: si sponsa sponso ea mente tradiderits res, ut non ante eius fieri vellet quam nuptiae secutae sint, usu quoque capio cessabit: si tamen non evidemer id actum fuerit, credendum esse id agi Iulianus ait, ut statim res eius fiant, et, si alienae sint, visucapi possint: quae sententia mhi probabilis videtur. Ante nuptias autem non pro dote usucapit, sed pro suo. 
Son olarak Proculus'a ait bir metni ele alalım [ $\left.{ }^{0}\right]$. Uzunca olan bu metnin muhtevasını şöyle hülâsa edebiliriz: Kul olan bir kız (ancilla) hür bir erkekle evleniyor, ve ona cihaz olarak bir miktar para veriyor. Hür bir erkekle bir kulun evlenmesine hukukan cevaz olmadığından, ortada meşru bir cihaz yoktur, ve dolayısiyle erkeğe verilen paranın tediyesi sebepsizdit: Binaenaleyh, bu meblağ evlenmeden önce hangi şahsa ait idiyse, onun olarak kalacaktır (mansit eius cuius fuerat antequam eo nomine viro traderetur). Fakat Proculus bir kayıt koşuyor: Şu kadar ki,tesadüfen o meblağ usucapio edile (nisi forte usucapta est). Metnimiz burada bitse, bu son kayit çok mânidar, ve bütün gördüklerimiz metinlere aykırt olabilirlerdi. Zira dediğimiz gibi, hür romalılar ile kullar arasında bir evlenme akti mümkün olmadığından, böyle bir cihaz tesisi tasavvur edilemez. Şu halde, yalnız farazi değil, imkânsız bir illete istinat eden bir usucapio ile karşılaşmıs olurduk. Bereket versin Proculus devam ederek, usucapio'nun cihaza istinaden değil, meblağı kendi hesabına yedinde bulundurmak (pro su o possidento) gibi umumi bir temlik sebebi ile vukua geleceğini söyliyor. Şu halde paranın usucapio suretiyle erkek tarafindan iktisabedilmesi, bu para evlenmeden ve binaenaleyh cihaz vasfını almadan önce verilmişse mümkün olacaktır.

Bu mïlâhazalar ise usucapio hususunda meşru sebep mefhumunun Roma hukukçuları tarafından ne geniş mânada kullanildığının bariz bir misalidir.

Gerek bağıșlamaya, gerek cihaza ait ve tahlil ettiğimiz metinlerden şu neticeleri q̧ıartabilitsiniz:

Roma hukukunda usucapio, kanunumuzdaki müruruzamandan farklı olarak, bir sebebe istinat etmelidir, ve bu sebep meşru olmalıdır. Şayet usucapio bağışlamaya müstenitse, hibe hukukan hükümsüz olmamalıdır. Usucapio'nun sebebi cihaz ise, muteber bir evlenme muvacehesinde bulunmaliyız.

Fakat bu meşru sebep (justa causa) mefhumu, bazı Roma hukukçuları tarafından çok geniş tutulmuştur. Oldukça müphem olan «pro suo» sebebini kabul etmişler, ve tarafların hüsnüniyeti halinde, fasit olan muameleleri dahi birtakım mülâhazalarla usucapio illeti olarak ileri sürmüşlerdir. Tarafların hüsnüniyeti Neratiüs'lerce, Proculus'larca en mühim unsur addedilmiştir. Bu unsur tedricen ilk plâna geçince, meşru sebep şartı da yavaş yavaş ve kendiliğinden ikinci plâna geçmiş, silinmiş, ve netekim modern hukukta tamamiyle kaybolmuştur.

Dr. Pertev SUBAŞI

["] Dig. 23, 3, 67 . 